\title{
Oswald Jonas 1897-1978
}

In 1965 my stepfather Oswald Jonas, then 68 years old, faced a difficult decision. Retired from Roosevelt University in Chicago where he had taught since 1942, he was currently lecturing at the Music Academy in Vienna. Should he settle in Vienna, his original home, or should he return to his adopted country? Many factors were pulling in both directions when a temporary answer came in the form of an unexpected invitation to be Regents' Professor at the University of California, Riverside, for the academic year 1965/66. He accepted delightedly. Although neither he nor my mother was acquainted with Riverside, California had always been their favorite state. Indeed, some of his earliest American musical contacts had been made at Berkeley.

The "temporary answer" was to become happily permanent. Thanks to the warm, enthusiastic reception by faculty and students alike, thanks to their openminded response to his highly individual approach to music, thanks particularly to the great personal friendship of Professor William Reynolds, then Department Chairman, and his family, Riverside became a new home. When the Regents' Professorship was over, Jonas remained as Adjunct Professor until his death in 1978.

Over the years, Jonas's work on manuscripts and editions led to his gradual acquisition of an excellent library of first and rare editions. Additionally, he received a substantial part of the Nachlass of Heinrich Schenker from his friend and first student, the Viennese musicologist Erwin Ratz. Ratz, who had heroically rescued Mrs. Schenker twice from concentration camps during the Hitler years, was unable to prevent her final fate; before being taken away by the Gestapo, she entrusted her husband's remaining papers (letters, music, manuscripts and his voluminous diaries) to him. Jonas devoted his last years' work almost exclusively to this fascinating material. It seems entirely appropriate that the University which was so hospitable and enabled him to work freely during those years should be the recipient and guardian of his unique library. 